\title{
Mediation Analysis of the Role of Air Pollution on the Relationship between Road Network Density and Cognitive Function: Results from a Cross-Sectional Study among Adults Age 60 and Older in Liaoning, China
}

\section{Xue Bai}

China Medical University

Jiaxin Wei

China Medical University

Dechun Luan

Liaoning Provincal Center for Disease Control and Prevention

Mengting Liu

China Medical University

Yonghui Gong

China Medical University

Qian Gao ( $\sim$ qgao@cmu.edu.cn )

China Medical University https://orcid.org/0000-0002-6291-6108

\section{Research}

Keywords: Air pollution, Cognitive function, Road network density, Suppressing effect, Mediating effect, Built environment

Posted Date: December 9th, 2020

DOI: https://doi.org/10.21203/rs.3.rs-122192/v1

License: (c) (i) This work is licensed under a Creative Commons Attribution 4.0 International License.

Read Full License 


\section{Abstract}

Background: Research on the relationship between road network density and cognitive function is lacking, and air pollution is related to both issues.

Objective: We examined the mediating role of air pollution in relationship to road network density and cognitive function of older adults in Liaoning, China.

Methods: This analysis included 745 adults age 60 and older. We obtained road network density for total roads, main roads, secondary roads, and other roads by OpenStreetMap and QGIS. We used air quality index (AQI) for the whole year, heating period, and nonheating period to assess individual air pollution exposure levels in different periods. We measured cognitive function using the Mini-Mental State Examination (MMSE). We used mediation analysis to evaluate the role of air pollution in the relationship between road network density and cognitive function.

Results: The relationship between total road network density and global cognitive function was positive $(\beta>0, p<0.01)$, and air pollution had a suppressing effect. The main road network density and cognitive function were negatively correlated, and the mediating effect of air pollution for all three periods accounted for $81.69 \%-90.09 \%$ of the total effects. The other road network density and cognitive function were positively correlated, and the suppressing effect of air pollution for all three periods accounted for $10.06 \%-18.50 \%$ of the total effects. The secondary road network density and cognitive function were positively correlated, and the suppressing effect of air pollution in the whole year and heating period accounted for $21.06 \%$ and $26.10 \%$ of the total effects, respectively. During nonheating period, the suppressing effect of air pollution was not statistically significant $[\beta=-0.018$; standard error $(S E)=$ $0.014 ; 95 \%$ confidence interval $(\mathrm{Cl}):-0.046,0.007]$.

Conclusion: Because the different categories of road network density have different relationships with cognitive function, air pollution had different effects on these relationships.

\section{Introduction}

China is experiencing rapid growth in its older population because of substantial declines in both fertility and mortality. The proportion of individuals age 60 years and older will increase from $13.26 \%$ of the Chinese population in 2010 to $25.1 \%$ in 2030 [1]. Research has suggested that cognitive function generally declines with aging. Elderly people are especially sensitive to physical and social surroundings and also are more vulnerable than younger adults to the environment [2]. Previous research has identified multiple individual risk factors that are associated with cognitive impairment and decline [3]. Recently, a growing number of researchers have looked beyond individual-level factors to consider the role of the built environment (BE) for cognition in older adults. Several BE features, such as land use mix, natural environment availability, and street connectivity, have been identified as being related to dementia and cognitive decline [4-6]. Road network density, as an important component of the BE, is an index used to evaluate the traffic conditions of a certain area and to measure the level of urban road construction. A 
higher density of the road network represents more convenient transportation [7]. Studies have shown that transportation is linked to physical activity $[8,9]$, which provides cognitive stimulation for older adults and also reduces vascular risk factors for dementia $[10,11]$. To our knowledge, however, no research has been reported on the relationship between road network density and cognitive function.

With further urbanization trends and an expanding road network, motor vehicle exhaust emissions have become a significant source of air pollution, which could further increase the risk of the population exposed to air pollution [12]. The association between air pollution and cognitive function has been well documented [13]. Studies have identified that air pollution was associated with a decrease in the total score of the cognitive function scale [14-16]. Long-term exposure to air pollution may accelerate cognitive decline in the early stages of dementia development [17]. Two studies on neuroimaging data of the elderly in the United States also found that living in areas with high concentrations of air pollutants is associated with changes in brain structure [18] and decreased brain volume [19]. Exposure to high levels of ambient air pollutants increases brain inflammation [20] and the accumulation of $\beta$-amyloid protein [21], both of which are related to the pathogenesis of Alzheimer's disease (AD). Thus, air pollution may play an intermediary role in the relationship between road network density and cognitive function.

The study of environmental characteristics, such as road network density and air pollution, can further our understanding of the potential influencing factors in the living environment that may affect cognitive health and help to improve cognitive health through environmental regulation, which holds great significance for the prevention and intervention of cognitive function decline. Therefore, to determine the relationship between road network density and cognition, and the associated role of air pollution, we conducted a cross-sectional study in Liaoning, China. The theoretical framework of this study is shown in Fig. 1.

\section{Methods}

\section{Study design and study population}

We performed this study in three cities (Shenyang, Anshan and Fuxin) in Liaoning Province, China, in 2017. We selected two municipal districts from each city, five community healthcare centers from each municipal district, and 25 elderly people from each community healthcare center. The community healthcare center manages multiple communities, and the participants include people who go to the community healthcare center for physical examinations but who are not patients. We recruited people age 60 and older who had the ability to take care of themselves and could complete the survey on their own. We excluded participants who suffered from dementia or AD, were deaf or nonspeaking, and had brain hemorrhage within six months of this study. We excluded three participants who had missing cognitive test scores and two participants who were missing years of community residence, leaving a final sample size of $n=745$. We obtained approval of the study from the Ethical Committee of the China Medical University, and we received consent from all participants. 


\section{Exposure assessment}

Road network density. Road network density refers to the ratio of the total mileage of the road network to a certain area. We use OpenStreetMap (OSM) to obtain the total length of all roads within a $0.8 \mathrm{~km}$ radius buffer centered on the centroid of community where the participant was located. We used QGIS v3.14.15 for road length acquisition and calculation. In addition, we divided the total roads into three categories, including the main roads, secondary roads and other roads. The main roads were the roads connecting cities, including national highways, provincial highways, and ring roads. The secondary roads were the roads connecting the main areas in the city, including arterial roads of the cities. Other roads referred to roads in various areas of the cities except for the main roads and secondary roads.

Air pollution. We used air quality index (AQI) to assess individual air pollution exposure levels. We obtained ambient air pollution data from the national urban air quality real-time release platform of China National Environmental Monitoring Centre. Considering that cognitive change is a long-term process, we collected air pollution data available in the three years before the survey. We derived an average measure of air pollution for each tract using daily monitoring data recorded at monitoring sites. We obtained the annual average value of air pollution by calculating the three-year air pollution monitoring data. We obtained the average value of air pollution during the heating period by calculating the air pollution data for the five months from November to March of the following year. We obtained the average value of air pollution in the nonheating period by calculating air pollution data for the seven months from April to October. The following inverse distance formula was used to obtain the average air pollution concentration within a $10 \mathrm{~km}$ radius centered on the centroid of the communities of participants lived:

$$
Z_{p}=\frac{\sum_{i=1}^{n} Z_{i} W_{i}}{\sum_{i=1}^{n} W_{i}}
$$

where $Z_{p}$ represents the interpolated air pollution value at the centroid of the communities of participants lived, $Z_{i}$ is the monitor-specific daily mean of air pollution, $W_{i}$ is the inverse distance function ( $1 /$ distance from tract centroid to monitor $\mathrm{i}$ ), and $\mathrm{n}$ is all monitors within a $10 \mathrm{~km}$ radius of the centroid of the communities of participants lived.

\section{Assessment of cognitive function}

We measure cognitive function with the Mini-Mental State Examination (MMSE) [22], which has previously been validated locally in the Chinese population with good sensitivity and specificity [23]. The MMSE is a 30-point questionnaire that is commonly used to briefly measure the cognitive status in the studies of older adults, with higher scores indicating better cognitive function. The test consists of a set of questions and tasks that assess a variety of domains, including orientation (10 points), memory (3 points), attention (5 points), recall (3 points), and language (9 points). 


\section{Covariates}

We collected information on age, gender, education, income, marital status, length of community residence, numbers of people living together, and chronic disease history by questionnaires. For education level, we categorized participants into two groups: those with nine or fewer years of education and those with ten years or more. Annual household income was placed into two groups: less than $¥$ 50000 and $¥ 50000$ or more. Marital status was organized according to those who currently were married, never married, divorced, or widowed. We additionally collected information on the length of community residence and the number of people living together with categories representing one people, two, three, and four and above. Because several chronic conditions are related to cognitive disorders in older age, the presence or absence of four chronic diseases, including hypertension, diabetes, hyperlipidemia, and coronary atherosclerotic heart disease, were recorded on the basis of self-reported information in the interview. If the respondent suffered from any of these diseases, we considered that they had chronic disease history. To control the air pollution caused by heating, we also collected the number of all chimneys of heating companies within a $0.8 \mathrm{~km}$ radius buffer centered on the centroid of community where the participant lived.

\section{Statistical Analysis}

We ran all statistical analyzes with the software package SPSS Statistics 23.0. We reported descriptive statistics of the study population and exposure assessment as percentages or means (standard deviation) and conducted mediation effect analyses with PROCESS [24]. To ensure that our models and main results were not merely due to specific model specifications, we first adjusted different covariates; included a set of demographic covariates (age, gender, education, annual household income) in model 1; and then included covariates representing family network resources (marital status and living together), chronic disease history, and length of community residence in model 2 , model 3 , and model 4 , respectively. Second, we examined the mediating effect of air pollution on different cognitive domains. Third, we examined the role of air pollution of three periods in the three categories of road network density and cognitive function.

\section{Results}

Table 1 shows the characteristics of the study population. The average total score of MMSE was $25.82 \pm$ 3.15. More information about exposure variables are presented in Table 2. 
Table 1

Characteristics of the study population $(n=745)$

\section{Characteristics}

Age, years

Gender

Male

Female

Education, years

$\leq 9$

$>9$

Marital status

Married

Never married

Divorced

Widowed

Annual household income, $¥$

$<50,000$

$\geq 50,000$

Numbers of people living together

1

2

3

4 and more

Length of community residence, years

Chronic disease history

No

Yes

Note: $\mathrm{SD}=$ Standard Deviation. Chronic disease history represents any positive medical history for

hypertension, diabetes, hyperlipidemia, or coronary atherosclerotic heart disease.

\section{$\mathrm{n}(\%) /$ mean \pm SD}

$67.8 \pm 6.2$

256 (34.4)

489 (65.6)

470 (63.1)

275 (36.9)

608 (81.6)

8 (1.1)

20 (2.7)

109 (14.6)

403 (54.1)

342 (45.9)

82 (11.0)

63 (8.5)

87 (11.7)

$20.2 \pm 14.4$

317 (42.6)

428 (57.4)
513 (68.9) 
Table 2

Descriptive statistics of the cognitive test (MMSE) total scores, cognitive domains and exposure variables

\begin{tabular}{|lll|}
\hline Characteristics & Mean \pm SD & Range \\
\hline Cognitive test & & \\
\hline Total Scores & $25.82 \pm 3.15$ & $(12,30)$ \\
\hline Orientation & $9.79 \pm 0.63$ & $(5,10)$ \\
\hline Memory & $2.02 \pm 0.89$ & $(0,3)$ \\
\hline Attention & $4.36 \pm 1.25$ & $(0,5)$ \\
\hline Recall & $1.82 \pm 1.05$ & $(0,3)$ \\
\hline Language & $7.83 \pm 1.01$ & $(2,9)$ \\
\hline Exposure variables & & \\
\hline Road network density, km/km² & & \\
\hline Total roads & $6.37 \pm 3.54$ & $(1.05,16.73)$ \\
\hline Main roads & $1.20 \pm 1.12$ & $(0,4.63)$ \\
\hline Secondary roads & $1.58 \pm 1.50$ & $(0,5.71)$ \\
\hline Other roads & $3.58 \pm 1.89$ & $(0.28,10.43)$ \\
\hline Air quality index, N/A & & $(0,8)$ \\
\hline The whole year & $91.49 \pm 9.31$ & $(76.56,112.50)$ \\
\hline Heating period & $112.34 \pm 15.68$ & $(86.82,141.61)$ \\
\hline Non-heating period & $76.60 \pm 5.05$ & $(69.23,91.71)$ \\
\hline Number of chimneys of heating companies & $1.59 \pm 1.79$ & $(0.8)$ \\
\hline Note: SD = Standard Deviation; MMSE, Mini-mental State Examination. & \\
\hline & & \\
\hline
\end{tabular}

As seen in Table 3, the relationship between total road network density and global cognitive function was significant and positive $(\beta>0, p<0.01)$. The relationship between total road network density and global cognitive function remained significant after including AQI as a mediator $(\beta>0, p<0.01)$. Results showed that the relationship between total road network density and global cognitive function through AQI had a suppressing effect, and the suppressing effects remained significant and negative in all four models after adjusting by different covariates. The suppressing effect was $41.52 \%$ of the total effects after inclusion of the covariates related only to demographics. The suppressing effects of model 2 , which included the covariates related to family network resources; model 3 , which included the history of chronic disease; 
and model 4 which included the length of community residence were $40.58 \%, 40.56 \%$, and $40.95 \%$, respectively of the total effects.

Table 3

Total, direct, and indirect effects from mediation models adjusted by different covariates

\begin{tabular}{|llllll|}
\hline & $\beta$ & SE & LLCl & ULCl & Proportion \\
\hline Model 1 & & & & & \\
\hline Indirect & -0.111 & 0.014 & -0.141 & -0.085 & $41.52 \%$ \\
\hline Direct & 0.268 & 0.029 & 0.213 & 0.325 & \\
\hline Total & 0.157 & 0.026 & 0.105 & 0.208 & \\
\hline Model 2 & & & & & $40.58 \%$ \\
\hline Indirect & -0.108 & 0.014 & -0.135 & -0.082 & \\
\hline Direct & 0.265 & 0.029 & 0.208 & 0.322 & $40.56 \%$ \\
\hline Total & 0.157 & 0.026 & 0.107 & 0.210 & \\
\hline Model 3 & & & & & \\
\hline Indirect & -0.109 & 0.014 & -0.139 & -0.084 & $40.95 \%$ \\
\hline Direct & 0.269 & 0.030 & 0.211 & 0.327 & \\
\hline Total & 0.160 & 0.026 & 0.108 & 0.211 & \\
\hline Model 4 & & & & & \\
\hline Indirect & -0.111 & 0.014 & -0.140 & -0.086 & \\
\hline Direct & 0.271 & 0.030 & 0.214 & 0.332 & \\
\hline Total & 0.160 & 0.026 & 0.111 & 0.214 & \\
\hline Note & & & & & \\
\hline
\end{tabular}

Note: SE, standard error; LLCl, lower limit confidence interval; ULCI, upper limit confidence interval.

Model 1 controlling for age, gender, education, annual household income.

Model 2 controlling for age, gender, education, annual household income, marital status, living together.

Model 3 controlling for age, gender, education, annual household income, marital status, living together and chronic disease history.

Model 4 controlling for age, gender, education, annual household income, marital status, living together, chronic disease history and length of community residence. 
Table 4 shows the results of the mediation analysis on the five dimensions of cognition. Except for the orientation, the role of air pollution on the relationship between total road network density and all four cognitive domains had a suppressing effect. Among them, the suppressing effect of AQI between total roads and recall accounted for $49.57 \%$ of the total effects.

Table 4

Total, direct, and indirect effects from mediation models of cognitive domains

\begin{tabular}{|llllll|}
\hline & $\beta$ & SE & LLCl & ULCI & Proportion \\
\hline Orientation & & & & \\
\hline Indirect & -0.004 & 0.003 & -0.011 & 0.002 & - \\
\hline Direct & 0.016 & 0.006 & 0.003 & 0.028 & \\
\hline Total & 0.011 & 0.006 & -0.001 & 0.023 & \\
\hline Memory & & & & & $40.31 \%$ \\
\hline Indirect & -0.018 & 0.004 & -0.026 & -0.011 & \\
\hline Direct & 0.045 & 0.009 & 0.026 & 0.063 & \\
\hline Total & 0.027 & 0.009 & 0.010 & 0.044 & \\
\hline Attention & & & & & \\
\hline Indirect & -0.027 & 0.006 & -0.040 & -0.016 & \\
\hline Direct & 0.068 & 0.014 & 0.042 & 0.094 & \\
\hline Total & 0.041 & 0.012 & 0.018 & 0.064 & \\
\hline Recall & & & & & \\
\hline Indirect & -0.041 & 0.006 & -0.053 & -0.030 & \\
\hline Direct & 0.082 & 0.012 & 0.059 & 0.104 & \\
\hline Total & 0.041 & 0.010 & 0.021 & 0.061 & \\
\hline Language & -0.021 & 0.004 & -0.029 & -0.013 & \\
\hline Indirect & 0.061 & 0.009 & 0.044 & 0.079 & \\
\hline Direct & 0.008 & 0.025 & 0.055 & \\
\hline Total & & & & & \\
\hline Note: SE, standard error; LLCl, lower limit confidence interval; ULCl, upper limit confidence interval. & \\
\hline Controlling for age, gender, education, annual household income, marital status, living together, & \\
\hline chronic disease history and length of community & residence. & & \\
\hline
\end{tabular}


Table 5 shows that the secondary road network density $[\beta=0.366$; standard error $(\mathrm{SE})=0.062 ; 95 \%$ confidence interval $(\mathrm{Cl}): 0.248,0.488]$ and other road network density $(\beta=0.452 ; \mathrm{SE}=0.052 ; 95 \% \mathrm{Cl}$ : $0.349,0.556)$ have a positive correlation with global cognitive function. The main road network density was negatively correlated with global cognitive function $(\beta=-0.349 ; \mathrm{SE}=0.115 ; 95 \% \mathrm{Cl}$ : $-0.573,-0.122)$. The role of air pollution on the relationship between secondary road network density and other roads and global cognitive function throughout the year had a suppressing effect that accounted for $21.06 \%$ and $17.93 \%$, respectively, of the total effects. The role of air pollution on the relationship between main road network density and global cognitive function throughout the year had a mediating effect that accounted for $90.09 \%$ of the total effects.

Table 5

Total, direct, and indirect effects from different categories of road network density to cognitive function on the basis of annual average AQI

\begin{tabular}{|llllll|}
\hline & $\beta$ & SE & LLCl & ULCl & Proportion \\
\hline Main roads & & & & & \\
\hline Indirect & -0.314 & 0.069 & -0.457 & -0.182 & $90.09 \%$ \\
\hline Direct & -0.035 & 0.143 & -0.313 & 0.254 & \\
\hline Total & -0.349 & 0.115 & -0.573 & -0.122 & \\
\hline Secondary roads & & & & & $21.06 \%$ \\
\hline Indirect & -0.098 & 0.019 & -0.138 & -0.062 & \\
\hline Direct & 0.463 & 0.064 & 0.341 & 0.589 & \\
\hline Total & 0.366 & 0.062 & 0.248 & 0.488 & \\
\hline Other roads & & & & & \\
\hline Indirect & -0.099 & 0.016 & -0.132 & -0.070 & \\
\hline Direct & 0.551 & 0.054 & 0.447 & 0.658 & \\
\hline Total & 0.452 & 0.052 & 0.349 & 0.556 & \\
\hline Note: SE, standard error; LLCl, lower limit confidence interval; ULCl, upper limit confidence interval. & \\
\hline $\begin{array}{l}\text { Controlling for age, gender, education, annual household income, marital status, living together, } \\
\text { chronic disease history and length of community residence. }\end{array}$ & & \\
\hline
\end{tabular}

Table 6 shows that after controlling for the number of chimneys of heating companies, secondary road network density $(\beta=0.369 ; \mathrm{SE}=0.062 ; 95 \% \mathrm{Cl}: 0.253,0.492)$ and other road network density $(\beta=0.469$; $\mathrm{SE}=0.052 ; 95 \% \mathrm{Cl}: 0.368,0.570)$ had a positive correlation with global cognitive function, but the main road network density was negatively correlated with global cognitive function $(\beta=-0.359 ; \mathrm{SE}=0.114$; 
$95 \% \mathrm{Cl}:-0.584,-0.132)$. The mediating effect of AQI during the heating period between the main roads and global cognitive function accounted for $83.90 \%$ of the total effect; the suppressing effect of AQI between secondary roads and global cognitive function accounted for $26.10 \%$ of the total effect; and the suppressing effect of AQI between other roads and global cognitive function accounted for $18.50 \%$ of the total effect.

Table 6

Total, direct, and indirect effects from different categories of road network density to cognitive function on the basis of average AQI during the heating period

\begin{tabular}{|c|c|c|c|c|c|}
\hline & $\beta$ & SE & LLCl & ULCI & Proportion \\
\hline \multicolumn{6}{|c|}{ Main roads } \\
\hline Indirect & -0.301 & 0.071 & -0.442 & -0.163 & $83.90 \%$ \\
\hline Direct & -0.058 & 0.145 & -0.338 & 0.229 & \\
\hline Total & -0.359 & 0.114 & -0.584 & -0.132 & \\
\hline \multicolumn{6}{|c|}{ Secondary roads } \\
\hline Indirect & -0.130 & 0.022 & -0.175 & -0.090 & $26.10 \%$ \\
\hline Direct & 0.499 & 0.066 & 0.369 & 0.626 & \\
\hline Total & 0.369 & 0.062 & 0.253 & 0.492 & \\
\hline \multicolumn{6}{|c|}{ Other roads } \\
\hline Indirect & -0.106 & 0.017 & -0.142 & -0.075 & $18.50 \%$ \\
\hline Direct & 0.575 & 0.055 & 0.469 & 0.685 & \\
\hline Total & 0.469 & 0.052 & 0.368 & 0.570 & \\
\hline \multicolumn{6}{|c|}{ Note: SE, standard error; LLCI, lower limit confidence interval; ULCI, upper limit confidence interval } \\
\hline
\end{tabular}

Table 7 shows that during the nonheating period, the relationship between secondary road network density and global cognitive function mediated by AQI was not statistically significant $(\beta=-0.018$; $S E=$ $0.014 ; 95 \% \mathrm{Cl}:-0.046,0.007)$. The mediating effect of $\mathrm{AQI}$ between the main roads and global cognitive function accounted for $81.69 \%$ of the total effect; the suppressing effect of AQI between other roads and global cognitive function accounted for $10.06 \%$ of the total effect. 
Table 7

Total, direct, and indirect effects from different categories of road network density to cognitive function on the basis of average AQI during the nonheating period

\begin{tabular}{|llllll|}
\hline & $\beta$ & SE & LLCl & ULCl & Proportion \\
\hline Main roads & & & & & \\
\hline Indirect & -0.285 & 0.054 & -0.397 & -0.183 & $81.69 \%$ \\
\hline Direct & -0.064 & 0.128 & -0.312 & 0.181 & \\
\hline Total & -0.349 & 0.113 & -0.575 & 0.181 & \\
\hline Secondary roads & & & & & - \\
\hline Indirect & -0.018 & 0.014 & -0.046 & 0.007 & \\
\hline Direct & 0.383 & 0.062 & 0.263 & 0.506 & \\
\hline Total & 0.366 & 0.061 & 0.247 & 0.490 & \\
\hline Other roads & & & & & \\
\hline Indirect & -0.051 & 0.011 & -0.075 & -0.030 & \\
\hline Direct & 0.503 & 0.054 & 0.400 & 0.609 & \\
\hline Total & 0.452 & 0.053 & 0.347 & 0.556 & \\
\hline Note: SE, standard error; LLCl, lower limit confidence interval; ULCl, upper limit confidence interval. & \\
\hline $\begin{array}{l}\text { Controlling for age, gender, education, annual household income, marital status, living together, } \\
\text { chronic disease history and length of community residence. }\end{array}$ &
\end{tabular}

\section{Discussion}

The results of this study indicated that total road network density was positively related to global cognitive function. Higher road network density not only promoted walking and cycling but also promoted the use of public transportation, such as walking to a bus station or train station, thereby increasing individual physical activity $[25,26]$. A survey on the potential risk factors of $A D$ showed that, on a global scale, inadequate physical activity is one of the two most important risk factors for the development of $A D$ [27]. Longitudinal studies also have confirmed the importance of physical activity in reducing dementia risk [28]. In a study of 2492 elderly Germans, regular participation in any additional physical activity was shown to reduce the incidence of dementia by $20 \%$ over the next 4.5 years [29]. In addition, a study of 803 elderly people living in the suburbs of Japan found that compared with those who were less active, those who claimed to have at least one day of physical activity per week had a $41 \%$ lower risk of developing $A D$ over the next 12 years [30]. Other longitudinal studies on the elderly have shown that compared with a sedentary lifestyle, any physical activity can reduce dementia or dementia-related 
mortality [31-33]. Therefore, we speculate that a dense road network can slow the progression of cognitive impairment by encouraging individuals living in the area to increase their physical activity.

With the expansion of the road network, however, the flow of motor vehicles will also increase, which will increase air pollution $[34,35]$. Therefore, in this study, we tested the mediating role of air pollution. Our results showed that air pollution weakened the promotion effect of total road network density on cognitive function. Although everyone may suffer the consequences of long-term exposure to air pollution, the elderly are more vulnerable. Increasing evidence has suggested that chronic ambient air pollution exposure may have neurotoxic effects in older individuals. In a multivariable-adjusted model for global cognitive function, the results demonstrated the association of black carbon with lower cognitive performance and cognitive decline in older individuals [36]. Another study evaluated the long-term exposure to particulate matter (PM) among 399 women 68-79 years old demonstrated an association between long-term exposure to air pollution and mild cognitive impairment [37]. Other researchers have reported that exposure to high concentrations of air pollutants will increase the risk of $A D$ [38] and vascular dementia [39]. It is precisely because of the harmful effect of air pollution on cognition that air pollution plays a suppressing role in the relationship between road network density and global cognitive function.

The majority of studies to date have reported the negative association of air pollution with global cognition or different domains of cognition, especially memory, language, and attention. A study assessed adults age 50 years and older living in areas with higher $\mathrm{PM}_{2.5}$ and found that participants had worse cognitive function, particularly for episodic memory but not for mental status [40]. Researchers also observed the relationship between estimated annual ozone exposure and reduced performance in specific central nervous system (CNS) functions. The results showed that the adverse effect was more pertinent to ozone-induced impairment in memory, attention, and coding ability but not in visuomotor speed [41]. Another study that examined a variety of air pollutants also showed that air pollution was inversely associated with logical memory abilities, executive functioning, and verbal learning performance [42]. The results of this study showed that air pollution mediated the relationship between road network density and memory, recall, language, attention, and calculation but not orientation. This finding was consistent with previous research results demonstrating that air pollution may be related to one or several dimensions of cognitive function.

Different roads have different characteristics and functions. Therefore, to further study the impact of different categories of roads on cognition, this study divided total roads into three categories. Results showed that the secondary road network density and other road network density remained positively correlated with cognitive function, but the main road network density was negatively correlated with cognitive function. The main roads generally are open to large cars with the largest traffic volume, thus connecting different cities and communicating with the outside world. The secondary road connects the main areas in the city, undertakes the main traffic tasks of the city, and forms the skeleton of the urban road network. Other roads play a role in collecting and distributing traffic and also have service functions. Compared with secondary roads and other roads, the main roads have few nonmotorized vehicles, larger 
traffic volume, and no restrictions on large vehicles. As a result, main roads have a limited effect on promoting people's physical activities such as walking and cycling. Thus, different categories of road have different impacts on people.

Liaoning Province is located in northeast China, from $38^{\circ} 43^{\prime}$ to $43^{\circ} 26^{\prime}$ north latitude. Its winter is long and cold, with a heating period of up to five months each year. In addition to vehicle exhaust emission, coalfired central heating is a significant source of air pollution in northern cities. Thus, based on the analysis of the mediating effect of air pollution throughout the year, in this study, we selected the heating period and controlled the number of chimneys of the heating companies for analysis to reduce the impact of air pollution from heating sources. For comparison, we also selected the nonheating period to eliminate air pollution from the heating source. Results showed that in the three periods, the mediating effect of air pollution in main road network density and cognitive functions, and the suppressing effect of air pollution in other road network density and cognitive functions did not change. The secondary road network density continued to have a positive relationship with cognition. Although the role of air pollution on the relationship between secondary road network density and global cognitive function during the nonheating period was not statistically significant, it revealed a suppressing effect trend. Because it is difficult to travel in cold and snowy winter, the use of bicycles and electric bicycles decreased significantly, and the use of motor vehicles increased. At the same time, the phenomenon of temperature inversion makes it difficult for pollutants to spread. All of these factors make air pollution more serious during the heating period and reduce individual physical activities, which in turn has a greater adverse effect on cognitive function. This analysis further confirmed that the role of air pollution on the relationship between road network density and cognitive function was stable.

Our study had some limitations. First, like other cross-sectional studies, the causal directions could not be examined. Second, although we adjusted many measured demographic characteristics and health-related characteristics of people, we were unable to control all covariates, and some variables that were not included, such as a sedentary lifestyle, depression, and unhealthy diet, may have affected our estimates. Third, individual exposure to air pollution in this study was estimated based on air monitoring data and may have been imperfect measures of personal exposure to ambient air pollution. Therefore, we applied inverse spatial interpolation to minimize exposure error resulting from spatial variation in air pollution concentrations, which reduced the error of using traditional closest environmental monitoring concentration to assess exposure.

Thus far, treatment for dementia and cognitive decline is not effective. With increased aging, cognitive decline and dementia have become important public health issues that seriously affect the mental health and quality of life of the elderly. Environmental characteristics that support active aging may reduce the risk of cognitive impairment and dementia. In recent years, scholars increasingly have turned their attention to researching the impact of the BE on cognitive functions [4, 43-45]. With the continuous development of urbanization, road networks have continued to expand. In China, by the end of 2019, the road network density was $52.21 \mathrm{~km} / 100 \mathrm{~km}^{2}$, an increase of $4.53 \mathrm{~km} / 100 \mathrm{~km}^{2}$ over 2015 [46]. This research found higher secondary road network density and other road network density could be beneficial 
to cognitive function by enhancing individual physical activity, but at the same time, this density also increased air pollution, thereby further impairing cognitive function. In addition, main road network density was positively correlated with lower cognitive function scores. Thus, when expanding road network construction, attention should be paid to reducing air pollution, thus ensuring that people can enjoy the convenience of transportation while also minimizing adverse effects on health.

\section{Abbreviations}

AD, Alzheimer's dementia; AQI, Air Quality Index; MMSE, Mini-Mental State Examination; $\beta, \beta$ eta coefficient; SE, Standard Error; $\mathrm{Cl}$, Confidence Interval; SD, Standard Deviation; LLCl, lower limit confidence interval; ULCl, upper limit confidence interval.

\section{Declarations}

\section{Ethics approval and consent to participate}

We obtained approval of the study from the Ethical Committee of the China Medical University, and we received consent from all participants.

\section{Consent for publication}

All authors a) have read the manuscript, b) agree the work is ready for submission to a journal, and c) accept responsibility for the manuscript's contents.

\section{Availability of data and materials}

Not applicable

\section{Competing interests}

The authors declare that they have no competing interests.

\section{Funding}

This study was supported by Natural Science Foundation of Liaoning Province (2019JH3/10300435).

\section{Authors' contributions}

XB: Conceptualization, Software, Formal analysis, Writing-original draft. JW: Conceptualization, Software, Writing-review \& editing. DL: Conceptualization, Writing-review \& editing. ML: Data curation, Investigation, Validation. YG: Investigation, Methodology, Validation. QG: Conceptualization, Writing-review \& editing, Supervision, Funding acquisition. All authors read and approved the final manuscript.

\section{Acknowledgments}


The authors gratefully acknowledge the dedicated efforts of all the participants in this study.

\section{References}

1. China National Bureau of Statistics Data [http://data.stats.gov.cn/easyquery.htm?cn=C01]

2. Lipnicki DM, Crawford JD, Dutta R, Thalamuthu A, Kochan NA, Andrews G, Lima-Costa MF, CastroCosta E, Brayne C, Matthews FE et al: Age-related cognitive decline and associations with sex, education and apolipoprotein E genotype across ethnocultural groups and geographic regions: a collaborative cohort study. PLoS Med 2017, 14(3):e1002261.

3. Reitz C, Brayne C, Mayeux R: Epidemiology of Alzheimer disease. Nat Rev Neuro/ 2011, 7(3):137-152.

4. Wu YT, Prina AM, Jones AP, Barnes LE, Matthews FE, Brayne C, Medical Research Council Cognitive F, Ageing S: Community environment, cognitive impairment and dementia in later life: results from the Cognitive Function and Ageing Study. Age Ageing 2015, 44(6):1005-1011.

5. Wu YT, Prina AM, Jones A, Matthews FE, Brayne C, Medical Research Council Cognitive F, Ageing Study C: The Built Environment and Cognitive Disorders: Results From the Cognitive Function and Ageing Study II. Am J Prev Med 2017, 53(1):25-32.

6. Ng TP, Nyunt MSZ, Shuvo FK, Eng JY, Yap KB, Hee LM, Chan SP, Scherer S: The Neighborhood Built Environment and Cognitive Function of Older Persons: Results from the Singapore Longitudinal Ageing Study. Gerontology 2018, 64(2):149-156.

7. Wang J, Huang $\mathrm{H}$ : Road network safety evaluation using Bayesian hierarchical joint model. Accid Anal Prev 2016, 90:152-158.

8. Jiang B, Liang S, Peng ZR, Cong H, Levy M, Cheng Q, Wang T, Remais JV: Transport and public health in China: the road to a healthy future. Lancet 2017, 390(10104):1781-1791.

9. Kerr J, Emond JA, Badland H, Reis R, Sarmiento O, Carlson J, Sallis JF, Cerin E, Cain K, Conway T et al: Perceived Neighborhood Environmental Attributes Associated with Walking and Cycling for Transport among Adult Residents of 17 Cities in 12 Countries: The IPEN Study. Environ Health Perspect 2016, 124(3):290-298.

10. Yen IH, Michael YL, Perdue L: Neighborhood environment in studies of health of older adults: a systematic review. Am J Prev Med 2009, 37(5):455-463.

11. Van Cauwenberg J, De Bourdeaudhuij I, De Meester F, Van Dyck D, Salmon J, Clarys P, Deforche B: Relationship between the physical environment and physical activity in older adults: a systematic review. Health Place 2011, 17(2):458-469.

12. Kumar P, Morawska L, Birmili W, Paasonen P, Hu M, Kulmala M, Harrison RM, Norford L, Britter R: Ultrafine particles in cities. Environ Int 2014, 66:1-10.

13. Friedrich MJ: Air Pollution Linked With Cognitive Harm in China. JAMA 2018, 320(15):1527.

14. Schikowski T, Vossoughi M, Vierkotter A, Schulte T, Teichert T, Sugiri D, Fehsel K, Tzivian L, Bae IS, Ranft $\mathrm{U}$ et al: Association of air pollution with cognitive functions and its modification by APOE gene variants in elderly women. Environ Res 2015, 142:10-16. 
15. Shehab MA, Pope FD: Effects of short-term exposure to particulate matter air pollution on cognitive performance. Sci Rep 2019, 9(1):8237.

16. Sun R, Gu D: Air pollution, economic development of communities, and health status among the elderly in urban China. Am J Epidemio/ 2008, 168(11):1311-1318.

17. Cleary EG, Cifuentes M, Grinstein G, Brugge D, Shea TB: Association of Low-Level Ozone with Cognitive Decline in Older Adults. J Alzheimers Dis 2018, 61(1):67-78.

18. Chen JC, Wang X, Wellenius GA, Serre ML, Driscoll I, Casanova R, McArdle JJ, Manson JE, Chui HC, Espeland MA: Ambient air pollution and neurotoxicity on brain structure: Evidence from women's health initiative memory study. Ann Neurol 2015, 78(3):466-476.

19. Wilker EH, Preis SR, Beiser AS, Wolf PA, Au R, Kloog I, Li W, Schwartz J, Koutrakis P, DeCarli C et al: Long-term exposure to fine particulate matter, residential proximity to major roads and measures of brain structure. Stroke 2015, 46(5):1161-1166.

20. Calderon-Garciduenas L, Kavanaugh M, Block M, D'Angiulli A, Delgado-Chavez R, Torres-Jardon R, Gonzalez-Maciel A, Reynoso-Robles R, Osnaya N, Villarreal-Calderon R et al: Neuroinflammation, hyperphosphorylated tau, diffuse amyloid plaques, and down-regulation of the cellular prion protein in air pollution exposed children and young adults. J Alzheimers Dis 2012, 28(1):93-107.

21. Levesque S, Surace MJ, McDonald J, Block ML: Air pollution \& the brain: Subchronic diesel exhaust exposure causes neuroinflammation and elevates early markers of neurodegenerative disease. $J$ Neuroinflammation 2011, 8:105.

22. Folstein MF, Folstein SE, McHugh PR: "Mini-mental state". A practical method for grading the cognitive state of patients for the clinician. J Psychiatr Res 1975, 12(3):189-198.

23. Ng TP, Niti M, Chiam PC, Kua EH: Ethnic and educational differences in cognitive test performance on mini-mental state examination in Asians. Am J Geriatr Psychiatry 2007, 15(2):130-139.

24. Hayes AF: Introduction to Mediation, Moderation, and Conditional Process Analysis: A regressionbased approach. New York: The Guilford Press; 2013.

25. Hou N, Popkin BM, Jacobs DR, Jr., Song Y, Guilkey D, Lewis CE, Gordon-Larsen P: Longitudinal associations between neighborhood-level street network with walking, bicycling, and jogging: the CARDIA study. Health Place 2010, 16(6):1206-1215.

26. Koohsari MJ, Sugiyama T, Mavoa S, Villanueva K, Badland H, Giles-Corti B, Owen N: Street network measures and adults' walking for transport: Application of space syntax. Health Place 2016, 38:8995.

27. Norton S, Matthews FE, Barnes DE, Yaffe K, Brayne C: Potential for primary prevention of Alzheimer's disease: an analysis of population-based data. Lancet Neurol 2014, 13(8):788-794.

28. Hamer $M$, Chida Y: Physical activity and risk of neurodegenerative disease: a systematic review of prospective evidence. Psychol Med 2009, 39(1):3-11.

29. Luck T, Riedel-Heller SG, Luppa M, Wiese B, Kohler M, Jessen F, Bickel H, Weyerer S, Pentzek M, Konig $\mathrm{HH}$ et al: Apolipoprotein E epsilon 4 genotype and a physically active lifestyle in late life: analysis of 
gene-environment interaction for the risk of dementia and Alzheimer's disease dementia. Psychol Med 2014, 44(6):1319-1329.

30. Rosness TA, Strand BH, Bergem AL, Engedal K, Bjertness E: Associations between Physical Activity in Old Age and Dementia-Related Mortality: A Population-Based Cohort Study. Dement Geriatr Cogn Dis Extra 2014, 4(3):410-418.

31. Kishimoto H, Ohara T, Hata J, Ninomiya T, Yoshida D, Mukai N, Nagata M, Ikeda F, Fukuhara M, Kumagai $\mathrm{S}$ et al: The long-term association between physical activity and risk of dementia in the community: the Hisayama Study. Eur J Epidemiol 2016, 31(3):267-274.

32. Llamas-Velasco S, Contador I, Villarejo-Galende A, Lora-Pablos D, Bermejo-Pareja F: Physical Activity as Protective Factor against Dementia: A Prospective Population-Based Study (NEDICES). J Int Neuropsychol Soc 2015, 21(10):861-867.

33. Wang S, Luo X, Barnes D, Sano M, Yaffe K: Physical activity and risk of cognitive impairment among oldest-old women. Am J Geriatr Psychiatry 2014, 22(11):1149-1157.

34. Forehead $\mathrm{H}$, Huynh $\mathrm{N}$ : Review of modelling air pollution from traffic at street-level - The state of the science. Environ Pollut 2018, 241:775-786.

35. Tonne C, Elbaz A, Beevers S, Singh-Manoux A: Traffic-related air pollution in relation to cognitive function in older adults. Epidemiology 2014, 25(5):674-681.

36. Power MC, Weisskopf MG, Alexeeff SE, Coull BA, Spiro A, 3rd, Schwartz J: Traffic-related air pollution and cognitive function in a cohort of older men. Environ Health Perspect 2011, 119(5):682-687.

37. Ranft U, Schikowski T, Sugiri D, Krutmann J, Kramer U: Long-term exposure to traffic-related particulate matter impairs cognitive function in the elderly. Environ Res 2009, 109(8):1004-1011.

38. Chang $\mathrm{KH}$, Chang MY, Muo $\mathrm{CH}, \mathrm{Wu} \mathrm{TN}$, Chen $\mathrm{CY}, \mathrm{Kao} \mathrm{CH}$ : Increased risk of dementia in patients exposed to nitrogen dioxide and carbon monoxide: a population-based retrospective cohort study. PLoS One 2014, 9(8):e103078.

39. Wu YC, Lin YC, Yu HL, Chen JH, Chen TF, Sun Y, Wen LL, Yip PK, Chu YM, Chen YC: Association between air pollutants and dementia risk in the elderly. Alzheimers Dement (Amst) 2015, 1(2):220228.

40. Ailshire JA, Crimmins EM: Fine particulate matter air pollution and cognitive function among older US adults. Am J Epidemiol 2014, 180(4):359-366.

41. Chen JC, Schwartz J: Neurobehavioral effects of ambient air pollution on cognitive performance in US adults. Neurotoxicology 2009, 30(2):231-239.

42. Gatto NM, Henderson VW, Hodis HN, St John JA, Lurmann F, Chen JC, Mack WJ: Components of air pollution and cognitive function in middle-aged and older adults in Los Angeles. Neurotoxicology 2014, 40:1-7.

43. Clarke PJ, Weuve J, Barnes L, Evans DA, Mendes de Leon CF: Cognitive decline and the neighborhood environment. Ann Epidemio/ 2015, 25(11):849-854. 
44. Watts A, Ferdous F, Moore KD, Burns JM: Neighborhood Integration and Connectivity Predict Cognitive Performance and Decline. Gerontol Geriatr Med 2015, 1.

45. Burton E: Streets ahead? The role of the built environment in healthy ageing. Perspect Public Health 2012, 132(4):161-162.

46. Ministry of Transport of the People's Republic of China of Statistics Data [http://xxgk.mot.gov.cn/2020/jigou/zhghs/202006/t20200630_3321335.html]

\section{Figures}

Model 1: $\quad \mathbf{Y}=\boldsymbol{\beta}_{1}+\mathbf{c X}+\varepsilon_{1}$

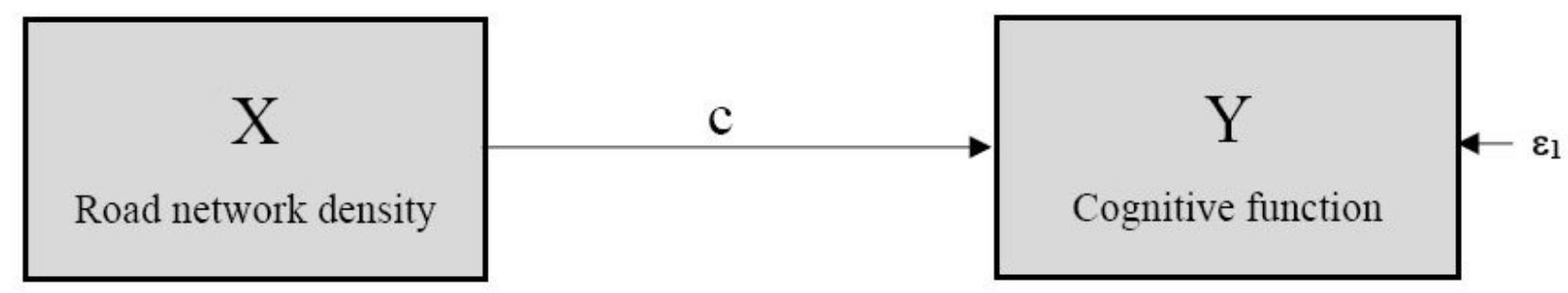

\section{Model 2: $\quad \mathrm{M}=\boldsymbol{\beta}_{2}+\mathbf{a X}+\varepsilon_{2}$ \\ $\mathbf{Y}=\boldsymbol{\beta}_{3}+\mathbf{c}^{\prime} \mathbf{X}+\mathbf{b} \mathbf{M}+\varepsilon_{3}$}

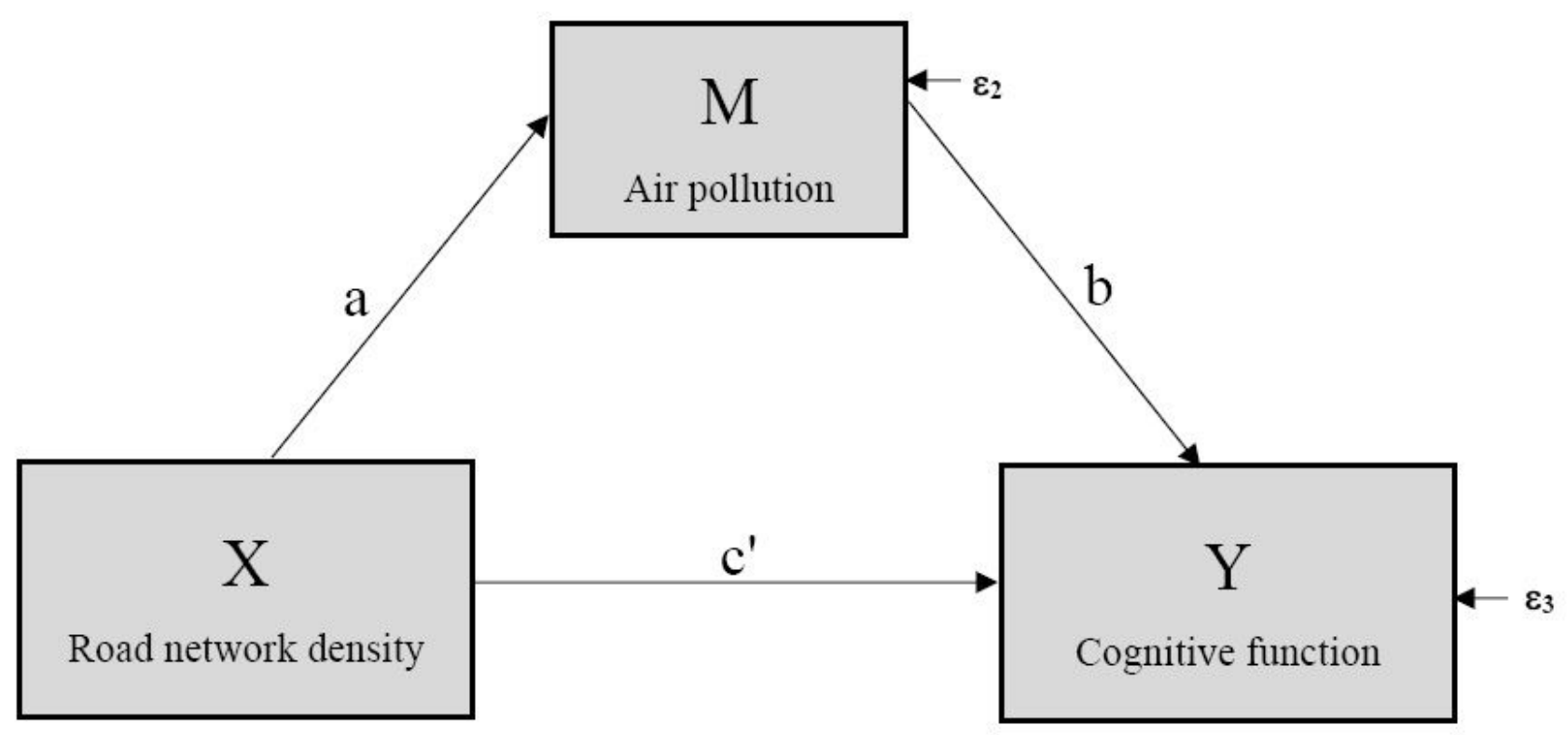

Figure 1

Theoretical framework of the mediation model. 